\title{
Urban morphological determinants of temperature regulating ecosystem services in two African Cities
}

\author{
Gina Cavan ${ }^{a, b^{*}}$, Sarah Lindley ${ }^{b}$, Fatimeh Jayeler ${ }^{c}$, Kumelachew Yeshitela ${ }^{d}$, Stephan Pauleit ${ }^{\mathrm{e}}$, Florian \\ Renner $^{\mathrm{e}}$, Susannah Gill ${ }^{b}$, Paolo Capuano ${ }^{c, f}$, Alemu Nebebe ${ }^{d}$, Tekle Woldegerima ${ }^{d}$, Deusdedit \\ Kibassag, Riziki Shemdoe ${ }^{g}$
}

aSchool of Science and the Environment, Manchester Metropolitan University, John Dalton Building, Chester Street, Manchester, M1 5GD, England.

${ }^{b}$ Geography, School of Environment, Education and Development, The University of Manchester, Arthur Lewis Building, Oxford Road, Manchester, M13 9PL, England.

'Department of Structures for Engineering and Architecture, University of Naples Federico II, Via Claudio, Naples, Italy

dEiABC, Addis Ababa University, P.O. Box 518, Addis Ababa, Ethiopia.

eDepartment of Landscape Planning \& Management, Technical University of Munich, Emil-RamannStrasse 6 D-85354 Freising, Germany.

fDepartment of Physics "E. Caianiello", University of Salerno, Fisciano (SA), Italy

gInstitute of Human Settlement Studies, Ardhi University, P.O. Box 35124, Dar Es Salaam, Tanzania.

*Corresponding author. Current address: School of Science and the Environment, Manchester Metropolitan University, John Dalton Building, Chester Street, Manchester, M1 5GD, England. Telephone: +44(0)161 247 1571. Email: g.cavan@mmu.ac.uk

\begin{abstract}
Urban green infrastructure provides important regulating ecosystem services, such as temperature and flood regulation, and thus, has the potential to increase the resilience of African cities to climate change. Differing characteristics of urban areas can be conceptualised and subsequently mapped through the idea of Urban Morphology Types (UMTs) - classifications which combine facets of urban form and function. When mapped, UMT units provide biophysically relevant meso-scale geographical zones which can be used as the basis for understanding climate-related impacts and adaptations. For example, they support the assessment of urban temperature patterns and the temperature regulation services provided by urban green structures. UMTs have been used for assessing regulating ecosystem services in European cities but little similar knowledge is available in an African context. This paper outlines the concept of UMTs and how they were applied to two African case study cities: Addis Ababa, Ethiopia and Dar es Salaam, Tanzania. It then presents the data and methods used to understand provision of temperature regulation services across the two cities.
\end{abstract}

In total, 35 detailed UMT classes were identified for Addis Ababa and 43 for Dar es Salaam. Modelled land surface temperature profiles for each of these UMTs are presented. The results demonstrate that urban morphological characteristics of UMTs, such as land surface cover proportions and associated built mass, have a much larger potential to alter neighbourhood level surface temperatures compared to projected climate changes. Land surface cover differences drive land surface temperature ranges over $25^{\circ} \mathrm{C}$ compared to climate change projections being associated with changes of less than $1.5^{\circ} \mathrm{C}$.

Residential UMTs account for the largest surface area of the cities, which are rapidly expanding due to population increase. Within the Residential UMTs, informal settlements and traditional housing areas are associated with the lowest land surface temperatures in Addis Ababa. These have higher 
proportions and better composition of green structures than other residential areas. The results have implications for planning policies in the cities. In Addis Ababa, the current urban renewal strategy to convert high density informal unplanned settlements into formal planned housing needs to explicitly account for green structure provision to avoid adverse effects on future supply of temperature regulation services. In Dar es Salaam, condominium UMTs have some of the largest proportions of green structures, and the best provision of temperature regulation services. In this case the challenge will be to maintain these into the future.

Keywords: Climate change; Africa; Cities; Urban Morphology; Land surface temperature; Land surface cover; GIS

\section{Introduction}

Africa is a continent particularly at risk from climate change. Temperature increases during the 21st century are expected to be in the range $3-4^{\circ} \mathrm{C}$ - about 1.5 times larger than the projected increase in global mean temperatures (Christensen et al., 2007; Gualdi et al., 2012). Furthermore, by 2035, around $50 \%$ of Africa's population is expected to live in urban areas (United Nations, 2012). Rates of urban development are still outpacing those of economic growth and infrastructure development in many urban areas. This, coupled with high levels of unemployment and inadequate standards of housing and services, means that those living in African cities are among the most vulnerable to climatic extremes and natural disasters such as heat waves, droughts, flooding, erosion and sea level rise.

The fast rate of urban development in response to rising demographic pressure - Africa is around $40 \%$ urban, growing at $1.27 \%$ per annum (United Nations, 2012) - and in particular, unplanned development, also threatens urban ecosystems. This is a particularly topical issue since urban ecosystems can provide a range of benefits for human health and wellbeing that arise as a result of ecosystem structure and functioning. The Millennium Ecosystem Assessment frames these ecosystem services as being associated with supporting, cultural, provisioning and regulating roles (MEA, 2005). The regulating roles of urban ecosystems are of particular relevance for meeting the challenges of planning for future climate variability. Regulating services encompass benefits obtained from the regulation of ecosystem-related processes, including those of climate, water, carbon and some human diseases (MEA, 2005). This paper focuses specifically on local climate regulation services.

Despite the recognised importance of climate regulation services, such non-marketed services provided by ecosystems remain unrecognised due to their less tangible nature, and as a result are regularly degraded (MEA, 2005; Busch et al., 2012). Adebayo (1990) notes that building and urban design in tropical Africa rarely takes account of local climatic conditions, due to a history of external influence, the rapid increase of slums, planners lacking training and knowledge, the political environment, and a lack of research on local urban climates. Unplanned development (e.g. when this acts as a barrier to sea breeze) is potentially the biggest threat to climate regulating services for human thermal comfort (Emmanuel and Johansson, 2006). Unplanned development may heighten the risk of heat-related mortality (McMichael et al., 2008), particularly given the association between high excess mortality for heat-related deaths and informal housing (Scovronick and Armstrong, 2012). Improving thermal performance of low cost housing - formal and informal - was identified as an important modifier in reducing heat-related mortality (Scovronick and Armstrong, 2012), but changes to other facets of the built environment that act to mitigate the Urban Heat Island (UHI) effect are also important, including the role of urban green space. 
The value of urban green spaces in providing local climate regulation services is widely recognised (Bolund and Hunhammar, 1999; Gill et al., 2007; Bowler et al., 2010; Niemela et al., 2010; Cavan et al., 2011; Cilliers et al., 2012). Specific direct and indirect benefits of green space associated with climate include flood water retention, improved infiltration, ground stabilisation, and heat stress relief through evapotranspiration and shading (Anderson, 2006; Lafortezza et al., 2009; Bartens et al., 2009). The composition of land cover, in particular, the percentage cover of buildings, is known to have a significant effect on land surface temperatures (Zhou et al., 2011). The spatial configuration of green space also affects land surface temperatures, though to a lesser extent (Zhou et al., 2011). Further, the combination of land surface cover types also has an effect on reducing temperatures, with shade trees over grass found to be the most effective landscape strategy in an arid environment (Shashua-Bar et al., 2009). At even finer scales, different plant species exhibit micro-environments, and trees and plants with a high level of evapotranspiration are associated with the lowest levels of human thermal discomfort (Georgi and Dimitriou, 2010).

Supply and delivery of sustainable ecosystem services depends upon the health, integrity and resilience of the ecosystem (Kumar and Wood, 2010; Bastian et al., 2012; Burkhard et al., 2012). Climate and extreme weather events can affect the condition of green structure and therefore the provision of ecosystem services. The availability of water resources is an important issue for urban green space in equatorial climates. For example, water stress during monsoonal dry periods is one of the most challenging threats for both semi-naturalised parks and street trees, and selection of species is important to adapt to the climate appropriately (Thaiutsa et al., 2008). Additionally, invasive species can affect the functionality and quality of green structure, and have a detrimental effect on the delivery of ecosystem services (Shackleton et al., 2006; McConnachie et al., 2008).

The disappearance of green space from urban areas is a significant threat globally and African cities are no exception. Fast urban expansion threatens the destruction of green space as land cover gradually changes from bushland, grassland and crops, to bare land, as trees are felled for construction and fuel, and areas are cleared for residential and industrial development. Given the high pace of change in African cities, it is important to develop a current understanding of the urban fabric and the ecosystem services associated with its green structures. Understanding of the baseline ecological and social fabric is also an essential element of any study investigating the impacts of climate change on an urban area. A baseline assessment can also be used to devise indicators for assessing trends in the quantity and quality of ecosystem services to understand the extent to which these are being sustained or lost over time, in order to inform appropriate policy responses (Layke et al., 2012). Such indicators can then be used to develop scenarios for spatial planning (Lindley et al., 2007), for example, to highlight the impact of different spatial planning policies on service provision (Schwarz et al., 2012). Despite the growing literature on the value of ecosystem services, Layke et al. (2012) find that indicators developed for most regulating services are weak at both global and subglobal scales, in part due to the higher priority given to quantifying marketed provisioning services, and fewer indicators exist for regional and local climate regulation. Moreover, very little analysis on climate regulation services has been undertaken in African cities (Roth, 2007; Cavan et al., 2011; Cilliers et al., 2012).

Since ecosystem service delivery is strictly linked to particular areas (Busch, 2012), it is necessary to utilise a spatial framework that connects urban form, social, cultural and biophysical processes. The framework of Urban Morphology Types (UMTs) or structural types has previously been applied in Europe to connect social and ecological states and drivers to establish a sound basis for green space planning (e.g. Pauleit and Duhme, 2000; Gill et al., 2007; Gill et al., 2008; Pauleit et al., 2010; La Rosa and Privitera, 2013). UMT units can be seen as "integrating spatial units linking human activities and natural processes" (Gill et al., 2008: 211), useful since biophysical units such as discrete green spaces may not be very well represented by existing administrative units and existing land use frameworks do not normally consider aspects of urban form and structure together. As urban morphology or structural units and types are the expression of past and recent human decisions on the use and 
form of land, they offer the potential to serve as an interface between natural and social sciences and planning (Breuste, 2006).

The objective of the study is to investigate the urban morphological characteristics of two African cities, with a focus on the spatial composition of urban green structures, in order to assess its impact on micro-climate regulation, specifically, the current and future regulation of temperatures.

\section{Methods}

\subsection{Study areas}

The selected case study cities in East Africa are Addis Ababa, Ethiopia, and Dar es Salaam, Tanzania. Addis Ababa, the capital city of Ethiopia is situated in the high plateaus of central Ethiopia, located at $9^{\circ} 2^{\prime} \mathrm{N} 38^{\circ} 44^{\prime} \mathrm{E}$. Addis Ababa has an area of 520 square kilometres and a population of 3,384,569 (2007 census estimate). The city experiences a warm temperate climate with dry winters and warm summers (CWB - Köppen-Geiger) (Kottek et al., 2006), due to its high-altitude location in the subtropics. Its high elevations - from around 2100 metres extending to over 3200 metres into the Entoto mountain chain to the north - moderate temperatures year round. Average monthly temperatures vary between $10-20^{\circ} \mathrm{C}$ and mean annual rainfall is around $700 \mathrm{~mm}$, although large differences in temperature and rainfall patterns occur across Addis Ababa depending on elevation and prevailing winds. Climate change projections for Addis Ababa (for 2041-2050 relative to 196170) indicate no significant changes in the seasonality of rainfall, but slight changes in monthly rainfall and potentially significant increases in rainfall amounts during March to May (CSIR \& CMCC, 2013). Projected increases in seasonal temperatures are in the region of $1.5-2^{\circ} \mathrm{C}$ (CSIR \& CMCC, 2013).

Dar es Salaam, Tanzania is situated on the eastern coast of Africa, located at $6^{\circ} 48^{\prime} \mathrm{S} 39^{\circ} 17^{\prime} \mathrm{E}$. The city has an area of around 1500 square kilometres mainland in addition to eight off-shore islands and a population of 4,364,541 (2012 census estimate). Dar es Salaam's climate is described as equatorial savannah, with a dry summer and generally hot and humid throughout the year (Aw - KöppenGeiger) (Kottek et al., 2006), with an average temperature of $29^{\circ} \mathrm{C}$ and peak temperatures occurring during the austral summer (December-February). The main features of Dar es Salaam's climate is the strong seasonal rainfall cycle, with two main rain seasons (March-May, Nov-Jan), induced by displacements of the Inter-tropical Convergence Zone (ITCZ). Average annual rainfall is around 1100 $\mathrm{mm}$. Sea breezes from the Indian Ocean influence both rainfall and temperatures in the city. Climate change projections for Dar es Salaam (for 2041-2050 relative to 1961-70) indicate no significant changes in the seasonality of rainfall, but potentially, significant increases in rainfall during the March-May "long rains", and seasonal temperature increases around $1.5-2^{\circ} \mathrm{C}$ (CSIR \& CMCC, 2013).

Whilst these cities vary in their climatic and topographic characteristics, both cities are exposed to climate-induced hazards including floods, erosion, and heat waves. Dar es Salaam is also exposed to droughts, sea level rise, cyclones, and coastal erosion. Climate change threatens to exacerbate these climate-induced hazards, with exposure also increasing due to rapid urban expansion and population growth. Ineffective urban planning results in many unplanned settlements and the urban poor often live in substandard quality housing, lacking basic infrastructure and community services, making them extremely vulnerable to the impacts of any climate-induced hazards.

Heat waves cause significant impacts on the populations in both Addis Ababa and Dar es Salaam. The impacts of a heat wave depend upon frequency, intensity, and also duration (Stephenson, 2008), where the capacity to adapt can be significantly reduced with prolonged exposure to high temperatures and humidity. Analysis of heat wave characteristics in the case cities was undertaken using observed data (1961-2011) and downscaled model projections (2030-2050) (CSIR and CMCC, 2012), whereby a heat wave is defined as a period in which the maximum temperatures are above 
the 90th percentile of the monthly distribution (evaluated over the climatological base period 19611990), for at least three days' duration. Heat wave duration and the number of hot days are strongly correlated, indicating that the rise in temperatures could mean an increase in the number of heat waves as well as a longer average duration of heat wave events. The frequency distribution of the duration of hot days has become longer-tailed with time. Observations and projections over 100 years (from 1950-70 to 2030-2050) show the number of events with maximum length lasting 5 days could increase from 3 to 24-33 in Dar es Salaam (depending on the IPCC scenarios) and from 3 to 3240 in Addis Ababa. The expected persistence of long-lived heat waves lasting approximately 1.5-2 weeks is also expected to increase in the future with respect to the climatological period 1961-1990. This evidence from climate change projections underlines the importance of considering appropriate adaptation strategies to urban temperature extremes in the selected case study cities.

\subsection{Characterisation of urban morphology and land cover}

The UMT characterisation approach has been increasingly adopted for urban ecological studies in Europe (e.g. Gill et al., 2007; Pauleit and Breuste, 2011; La Rosa and Privitera, 2013) and it is recognised as a useful framework for land use planning (Gill et al., 2008). The UMT approach involves characterising the city and its green structure. Its application in the context of African cities has considerable novelty, since whilst there are a small number of assessments with the same general principles (e.g. in North Africa (Moudon, 1997)), they do not have the scope of the current assessment. Lupala (2002), for example, focuses on characterising residential areas only in Dar es Salaam. UMT mapping has considerable benefit for ecosystem services assessment, due to the breadth of green structures considered, which are typically not included on land use maps. For example, in Dar es Salaam, rare and valuable mangroves which sustain important ecosystem functions and provide diverse goods and services can be delineated as a separate UMT category.

Whilst the general UMT methodology from Gill et al. (2008) was adopted, a new classification was developed for Dar es Salaam and Addis Ababa because African cities differ strongly from European cities. UMT maps were produced by digitising orthorectified aerial photographs and verifying with field surveys and local stakeholder participation. The reference year was dependent upon the availability and quality of orthophotos: 2011 for Addis Ababa and 2008 for Dar es Salaam; both in the dry season (December-February). For Dar es Salaam, UMT units were created by re-classifying an available land use map for 2008, and verified using the orthophotos (Cavan et al., 2012).

The mapped UMT categories provide comprehensive spatial information about urban form but do not provide information about the typical land surface cover proportions within these UMTs. Since important green structures exist outside the UMTs that are wholly or mostly green, such as agricultural land, it is also important to assess the land surface cover composition within these other UMTs to determine their green structure types, proportions, and thus, assess the associated ecosystem services that they provide.

Land surface cover assessment was carried out for each UMT category by visual interpretation of orthophotos following the methodology of Gill et al. (2008). Due to the large areas involved, a random point sampling strategy was devised to investigate the land surface cover on a point-bypoint basis, whereby the number of points analysed within each UMT category was proportional to the overall area coverage of the UMT category (Cavan et al., 2012). This process generates an average land cover profile for each UMT identified. The land surface cover assessment is valid for the dry season only as the orthophotos were taken in this season. Grasses are particularly prone to seasonal change and may appear as bare soil during the dry season (Cavan et al., 2012). Whilst rainfed agricultural crops are also highly seasonal, classification is aided through the visual context of field patterns and these areas are in any case likely to be subject to higher rates of land cover change 
through the year. For both grasses and crops the biophysical properties of the land covers associated with the functional properties of the morphology type will vary through the year in response to season and management practice. The results of the modelling are also therefore only reliable for the dry season.

\subsection{Energy exchange modelling for quantifying temperature regulation ecosystem services}

Whilst mapping air temperature differences across urban areas may seem the most obvious indicator for local temperature regulation, air temperatures are not easy to estimate without detailed small-scale measurements (Schwarz et al., 2011), relationships with land use classes are difficult to establish (Cheng et al., 2008), and air temperatures are less well correlated to outdoor human thermal comfort due to the variability of other weather parameters such as humidity and wind speed (Brown and Gillespie, 1995). In fact, the mean radiant temperature, incorporating the combined effects of air and surface temperatures is a better estimator of thermal comfort (Matzarakis et al., 1999), and land surface temperatures observed from satellite thermal infrared sensing have been shown to correlate well with heat-related mortality (Dousset et al., 2011; Laaidi et al., 2012). Analysis of land surface temperature is distinctly advantageous because it enables a spatially explicit depiction of the thermal state over large areas. This study uses a modelling approach which enables consideration of future conditions and urban scenarios. Modelled surface temperatures have previously been used as an indicator for calculating energy exchange in the urban environment (Whitford et al., 2001; Pauleit et al., 2005; Tratalos et al., 2007; Gill et al., 2007). Modelling the surface temperatures for each UMT category enables results to be mapped across the city at UMT level. Thus, temperature variations can easily be visualised across the city and highlight how average morphological characteristics can affect regulating ecosystem services at the sub-city level.

The surface temperature modelling approach is based upon an original model developed by Tso et al. $(1990,1991)$ for Singapore, its climate described as equatorial and fully humid (Af) by the Koppen-Geiger Index (Kottek et al., 2006). The Tso et al. (1990; 1991) model expresses the surface energy balance of an area in terms of its surface temperature, and is based on the simple instantaneous energy balance equation:

$R=H+L E+G+M$

Where $R$ is the net radiation flux to the earth's surface, $H$ is the sensible heat flux due to convection, $L E$ is the latent heat flux due to evaporation, $G$ is the conductive heat flux into the soil, and $M$ is the heat flux to storage in the built environment (Tso et al., 1991; 1990). The model output provides the surface and soil temperatures as a function of time on a hot, cloud free day. The model was developed and customised by Whitford et al. (2001), and more recently, was developed into a freely available online web tool ('STAR tools', The Mersey Forest and The University of Manchester, 2011). The STAR tools can produce outputs of surface temperatures across any urban area, after applying tailored input parameters. Therefore, all model parameter input values were adjusted as appropriate to account for localised climatic and land cover characteristics in the case study cities (Appendix A).

The proportion of green space, water and buildings are important determinants of the land surface temperature across local scales (Zhou et al., 2011). Accordingly, these terms are also accounted for in the model. A refined approach to incorporating land cover types was applied, based on Gill et al. (2007), and further modified to consider urban surface cover types specific to the African context (Cavan et al., 2012). The analysis of land surface cover types enables calculation of the evaporating fraction - the proportional cover of vegetation and water. 
Simulations of surface temperatures were undertaken for two time slices - a baseline and future time period. Climate projections data at $1 \mathrm{~km}$ resolution for both cities were obtained from Coupled General Circulation Model (CGCM) simulations, performed for the period 1961-2050, for the A2 IPCC emissions scenario (CSIR and CMCC, 2012). Six projections were obtained from downscaling six different coupled models, all ensemble models were analysed, and the $50^{\text {th }}$ percentile calculated. As the focus is on a hot, cloud free day, the $98^{\text {th }}$ percentile mean temperature in the dry season (December-February) was used as the reference air temperature.

A weighted built mass was determined for each UMT class. This accounted for the proportion of roads, buildings (including those associated with formal and informal settlement areas), and impervious surfaces within the UMT category, as determined by the land surface cover assessment. A weighted built mass for each UMT category (excluding Major roads UMT which has a different mass, see Appendix $\mathrm{C}$ ) was thus determined by Equation 1:

$$
M_{b(\mathrm{UMT})}=\left(M_{\mathrm{b}(\mathrm{OIS})} \times \%_{(\mathrm{OIS})}\right)+\left(M_{\mathrm{b}(\mathrm{Bi})} \times \%_{(\mathrm{Bi})}\right)+\left(M_{\mathrm{b}(\mathrm{Bii})} \times \%_{(\mathrm{BBi})}\right)
$$

Equation 1

where $M_{b}$ is built mass, OIS is other impervious surfaces, $B_{i}=$ Building type I (a building typical of a formal settlement area), $B_{i i}=$ Building type II (a building typical of an informal settlement area, Appendix B). The built mass for roads and other impervious surfaces is provided in Appendix $C$.

\section{Results}

UMT classification resulted in the recognition of 12 primary urban types and within those, 35 detailed UMT classes in Addis Ababa and 43 detailed UMT classes are evident in Dar es Salaam (Figure 1; Table 1). Whilst the area of Dar es Salaam is around three times larger than Addis Ababa, common to both cities is that the residential types account for the greatest surface area (Table 1). In Dar es Salaam, residential areas extend away from the urban core on the central eastern coast, following the major highway extending from the port to outer Dar es Salaam. The UMT map for Addis Ababa shows evidence of an urban core and also illustrates Addis Ababa's multi-nucleated character (Nvarirangwe, 2008). Recreation, retail, utilities and minerals account for less than $1 \%$ of the area in both cities. Over $40 \%$ of the land area of both cities is associated with sub-UMT classes which are primarily green in nature. Addis Ababa is fringed with the exotic plantation species Eucalyptus to the north. Addis Ababa has a large proportion of bare land, incorporating previously developed land areas. 


\section{(a)Addis Ababa}

\section{Urban morphology types}

1. AGRICULTURE
Field crops
Vegetable farms
2. VEGETATION
Plantation
Mixed forest
Riverine
Grassland
3. MINERALS \& QUARR
Mineral workings
4. RECREATION
Parks
Stadium/festival sites
Hotels
5. TRANSPORT
Major roads
Bus terminals
Rail
Airport
6. UTILITIES \& INF
Energy distribution
Water treatment
Refuse disposal
Cemeteries

7. RESIDENTIAL

Condominium

Villa \& single storey

Mud/wood construction

Mixed residential

8, COMMUNITY SERVICES

Education

Medical S

9. RETAIL

Formal shopping

Open markets

Mixed retail

10. INDUSTRY \& BUSINESS

Manufacturing

Offices

Palace

Storage \& distribution

Garages

Mixed industry

11. BARE LAND

Bare land

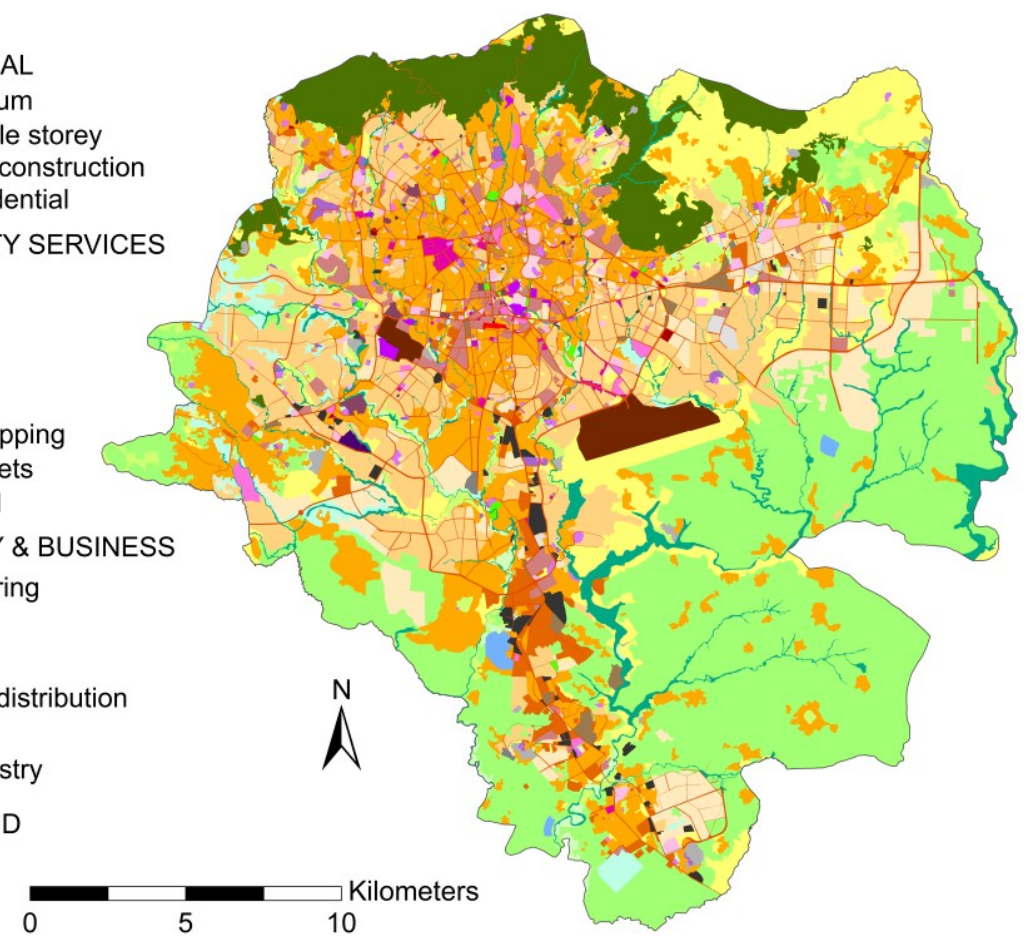

(b) Dar es Salaam

Urban Morphology Types

\begin{tabular}{l} 
1. AGRICULTURE \\
Field crops \\
Mixed farming \\
Horticulture \\
2. VEGETATION \\
Mixed forest \\
Riverine \\
Bushland \\
Mangrove \\
Marsh/ swamp \\
3. MINERALS \& QUARRIES \\
Mineral workings \\
4. RECREATION \\
Parks \\
Entertainment \\
Sports grounds \\
Other open space \\
Beach \\
Hotels \\
\hline 5. TRANSPORT \\
Major roads \\
Bus terminals \\
Rail \\
Airports \\
\hline Port \\
\hline
\end{tabular}
6. UTILITIES \& INF Energy production Water treatment
Refuse disposal Cemeteries

7. RESIDENTIAL Condominium

Villa \& single storey

Mud/wood construction Scattered settlement Mixed residential

8, COMMUNITY SERVICES Education

Medical

Religion Institutional Military

9. RETAIL

Formal shopping

Open markets

Mixed retail

Malls
10. INDUSTRY \& BUSINESS
Manufacturing
Offices
Storage \& distribution
Garages

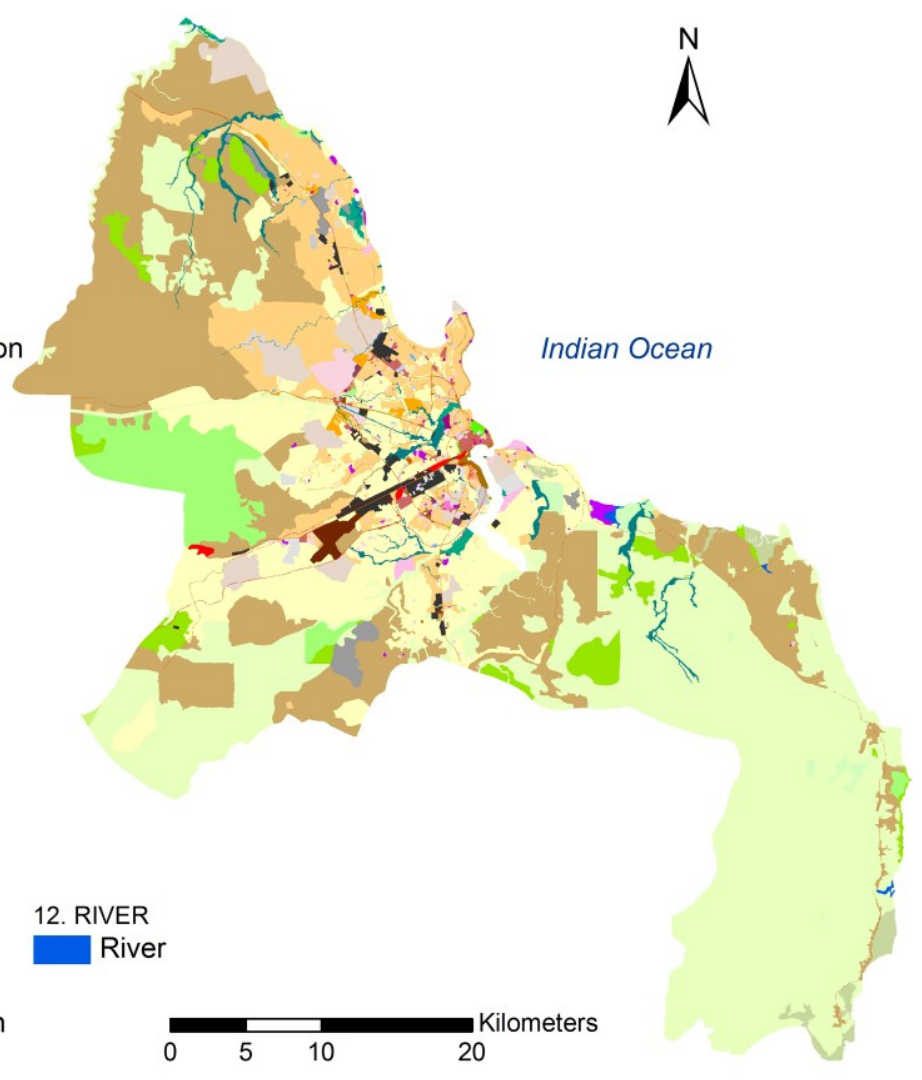

Figure 1: Urban Morphology Types for the case study cities (a) Addis Ababa (b) Dar es Salaam 
Table 1: Primary UMT statistics for Addis Ababa and Dar es Salaam

\begin{tabular}{|l|r|r|r|r|}
\hline \multirow{2}{*}{$\begin{array}{c}\text { High-level Urban } \\
\text { Morphology Type }\end{array}$} & \multicolumn{2}{|c|}{ Addis Ababa } & \multicolumn{2}{c|}{ Dar es Salaam } \\
\cline { 2 - 5 } & Area (ha) & \multicolumn{1}{c|}{$\%$} & Area (ha) & \multicolumn{1}{c|}{$\%$} \\
\hline 1. Agriculture & 14920 & 28.7 & 60711 & 40.4 \\
\hline 2. Vegetation & 7616 & 14.7 & 7703 & 5.1 \\
\hline 3. Minerals \& quarries & 192 & 0.4 & 1139 & 0.8 \\
\hline 4. Recreation & 181 & 0.3 & 1088 & 0.7 \\
\hline 5. Transport & 2427 & 4.7 & 1576 & 1.0 \\
\hline 6. Utilities \& infrastructure & 349 & 0.7 & 223 & 0.1 \\
\hline 7. Residential & 17978 & 34.6 & 69847 & 46.5 \\
\hline 8. Community Services & 760 & 1.5 & 5549 & 3.7 \\
\hline 9. Retail & 261 & 0.5 & 123 & 0.1 \\
\hline 10. Industry \& business & 2770 & 5.3 & 2084 & 1.4 \\
\hline 11. Bare land & 4507 & 8.7 & - & 0.0 \\
\hline 12. River & $*$ & 0.0 & 147 & 0.1 \\
\hline Total & 51961 & 100.0 & 150190 & 100.0 \\
\hline
\end{tabular}

*Included within vegetation class (riverine)

Results of the proportional land surface cover assessment for detailed UMT classes are provided in Figure 2. Both cities have a high amount of bare soil across all UMT categories, not just the agricultural and vegetation UMT categories. Formal shopping UMT has the highest proportion of formally constructed buildings in both cities. Overall, Dar es Salaam has higher proportions of vegetated surfaces across most UMT categories compared to Addis Ababa. 

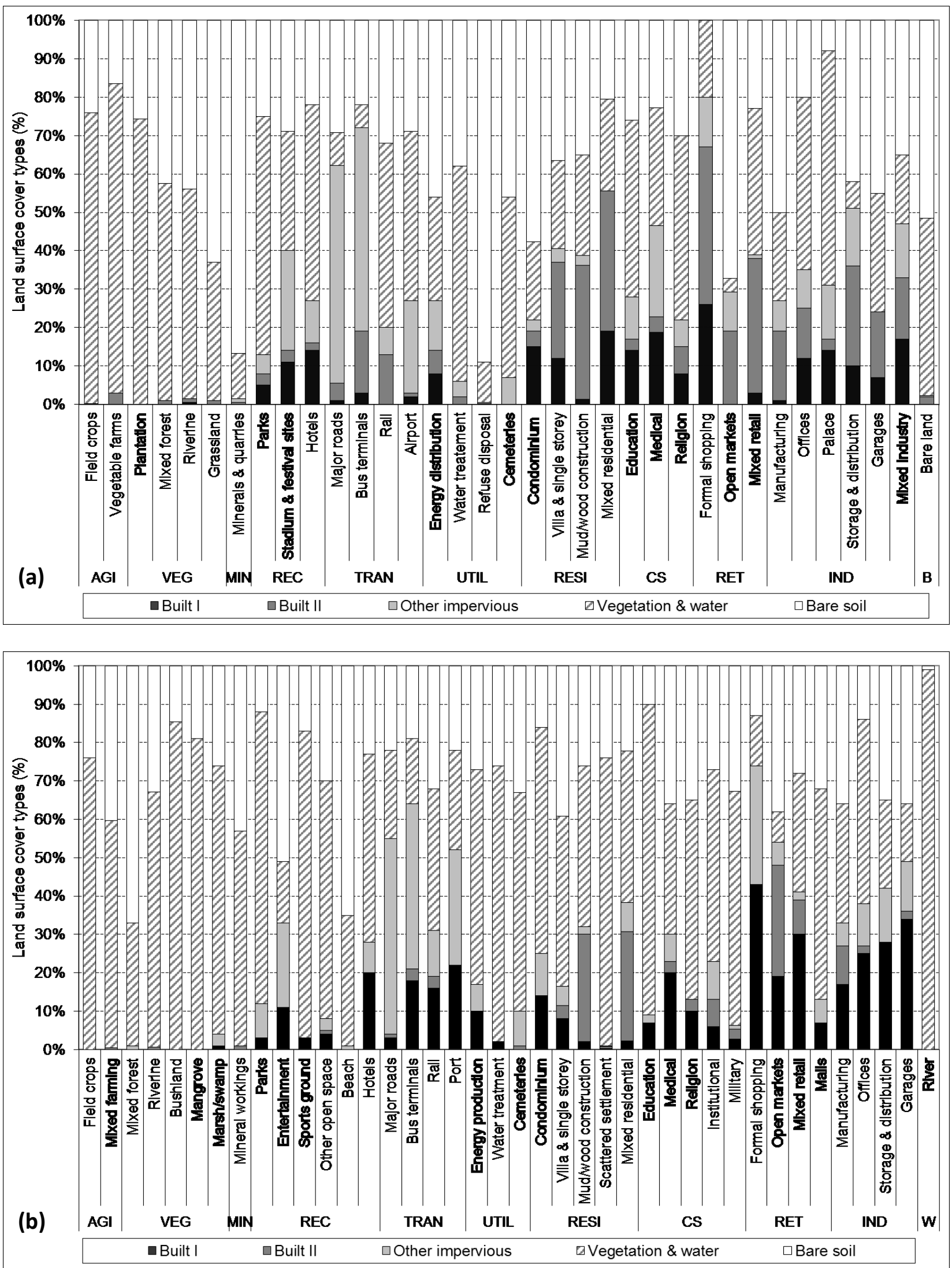

Figure 2: Proportional land surface cover for detailed UMT classes (a) Addis Ababa (b) Dar es Salaam. AGR=Agriculture; VEG=Vegetation; MIN=Minerals; REC=Recreation; TRAN=Transport; UTIL=Utilities \& infrastructure; RESI=Residential; $C S=$ Community Services; RET=Retail; IND=Industry \& business; $\mathrm{W}=$ Water; $\mathrm{B}=$ Bare land. 
These proportional land surface cover results can be mapped onto the UMT categories to visualise the spatial distribution of built and evapotranspiring surfaces across the cities (Figure 3). The maps illustrate that Addis Ababa is more built-up than Dar es Salaam, with approximately $18 \%$ of the land surface having over $40 \%$ built surfaces, compared to less than $1 \%$ for Dar es Salaam. Dar es Salaam has more evapotranspiring (green structures and water) surfaces, with around $45 \%$ of the land surface area having $40-60 \%$ vegetated surfaces, compared to around $20 \%$ for Addis Ababa. However, the administrative areas used in defining the bounds of a city have an effect here, particularly since the Dar es Salaam administrative area includes a large agricultural zone to the south.

(a)
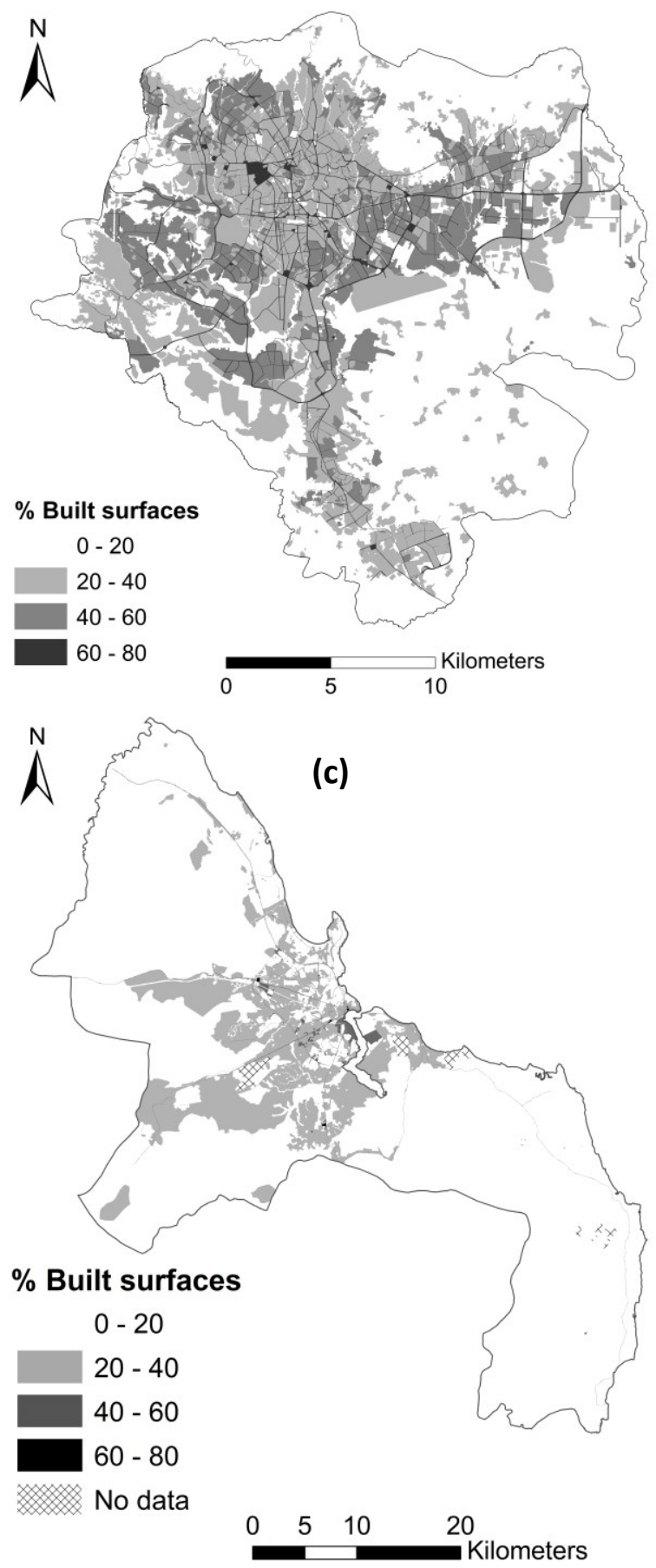

(b)
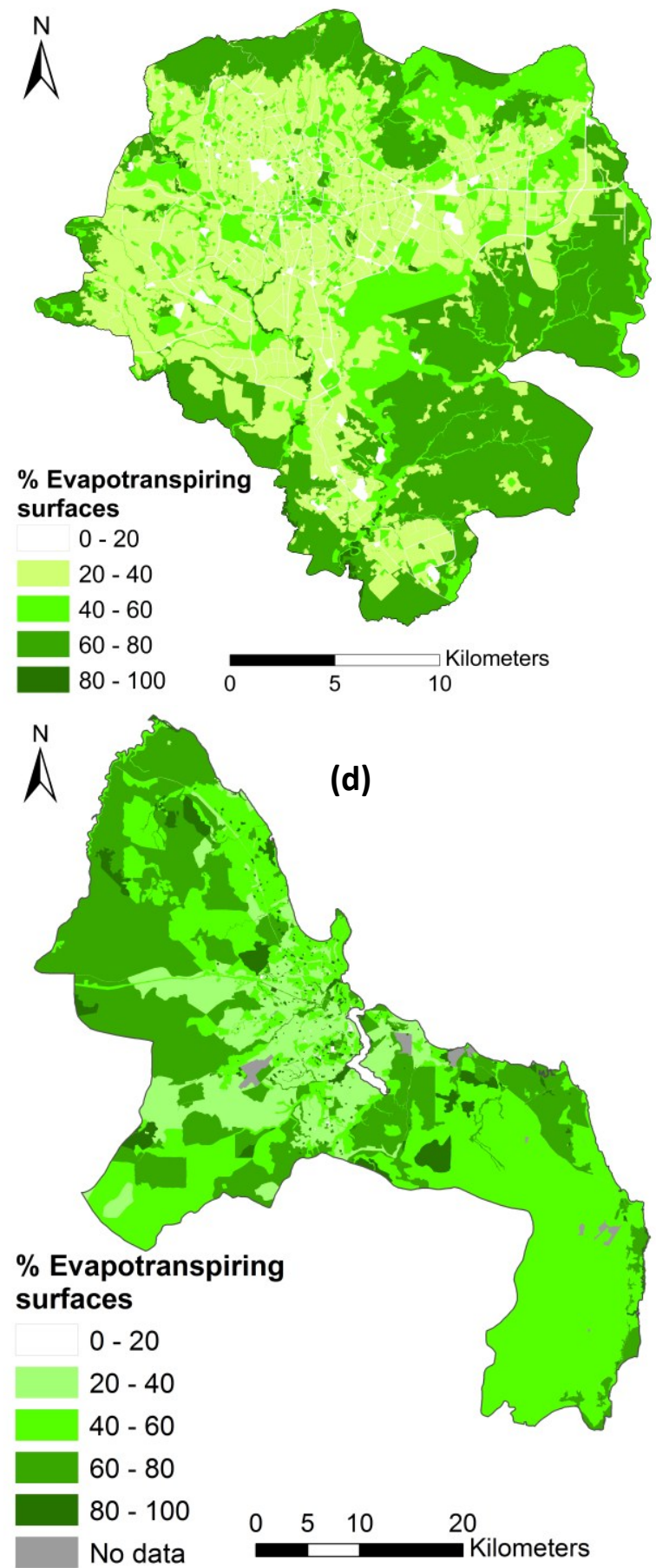

Figure 3: Built and evapotranspiring surfaces in the case study cities (a) Addis Ababa: built (b) Addis Ababa: evapotranspiring (c) Dar es Salaam: built (d) Dar es Salaam: evapotranspiring 
Figure 4 illustrates the great spatial variation in surface temperatures across the cities (driven by the distribution of UMTs), with the built-up areas clearly evident and associated with higher maximum temperatures. There is a large range in maximum temperatures, over $25^{\circ} \mathrm{C}$ difference between the highest value, Open markets UMT, and Vegetable farms UMT (Addis Ababa) / River UMT (Dar es Salaam). The spatial variation in maximum temperatures across the cities is actually much greater than the differences due to climate change projections, which increase air temperatures by around $1-1.5^{\circ} \mathrm{C}$ (2021-2050, A2 IPCC emissions scenario), translating to up to $1.5^{\circ} \mathrm{C}$ increase in surface temperatures. Thus, in terms of local temperature change, urban morphological change has the potential to have a much greater effect overall than impacts of climate change.

(a)

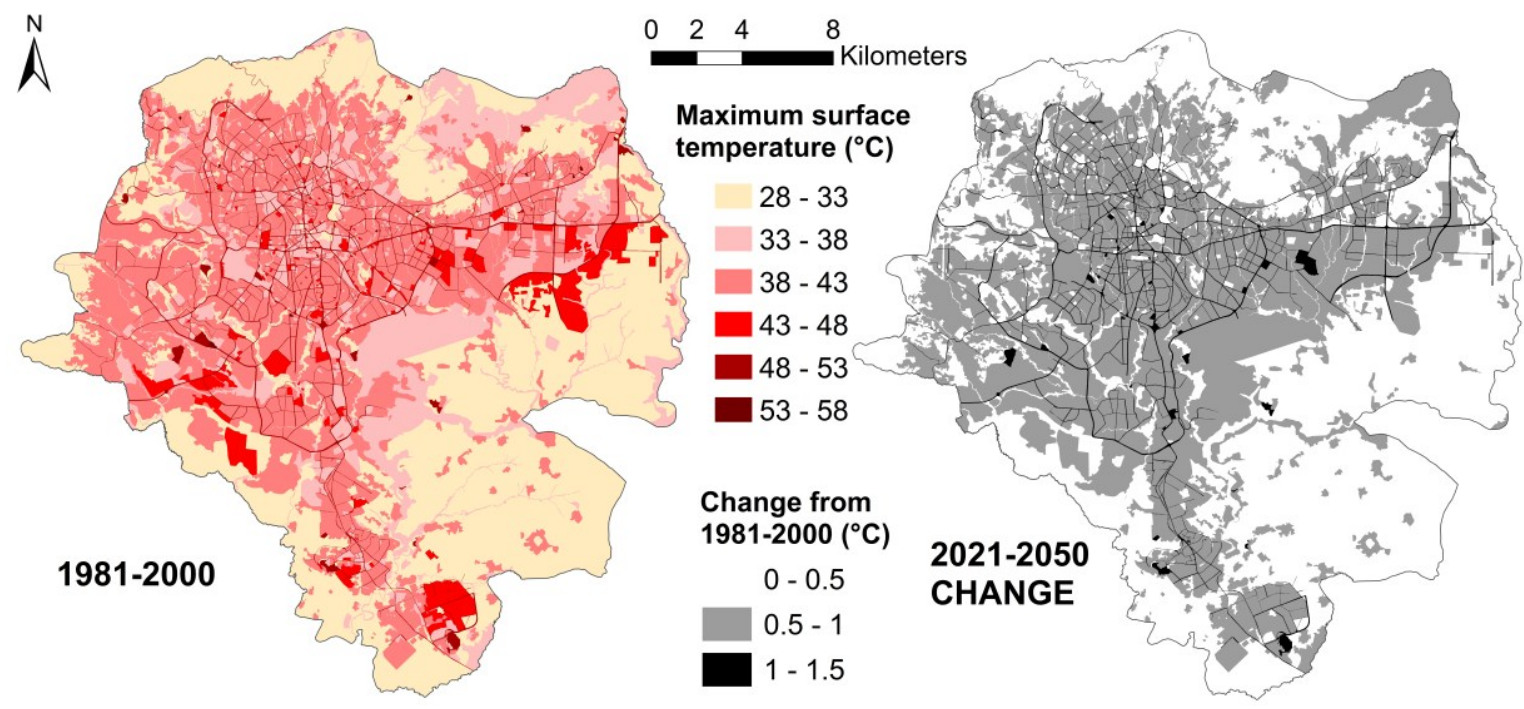

(b)

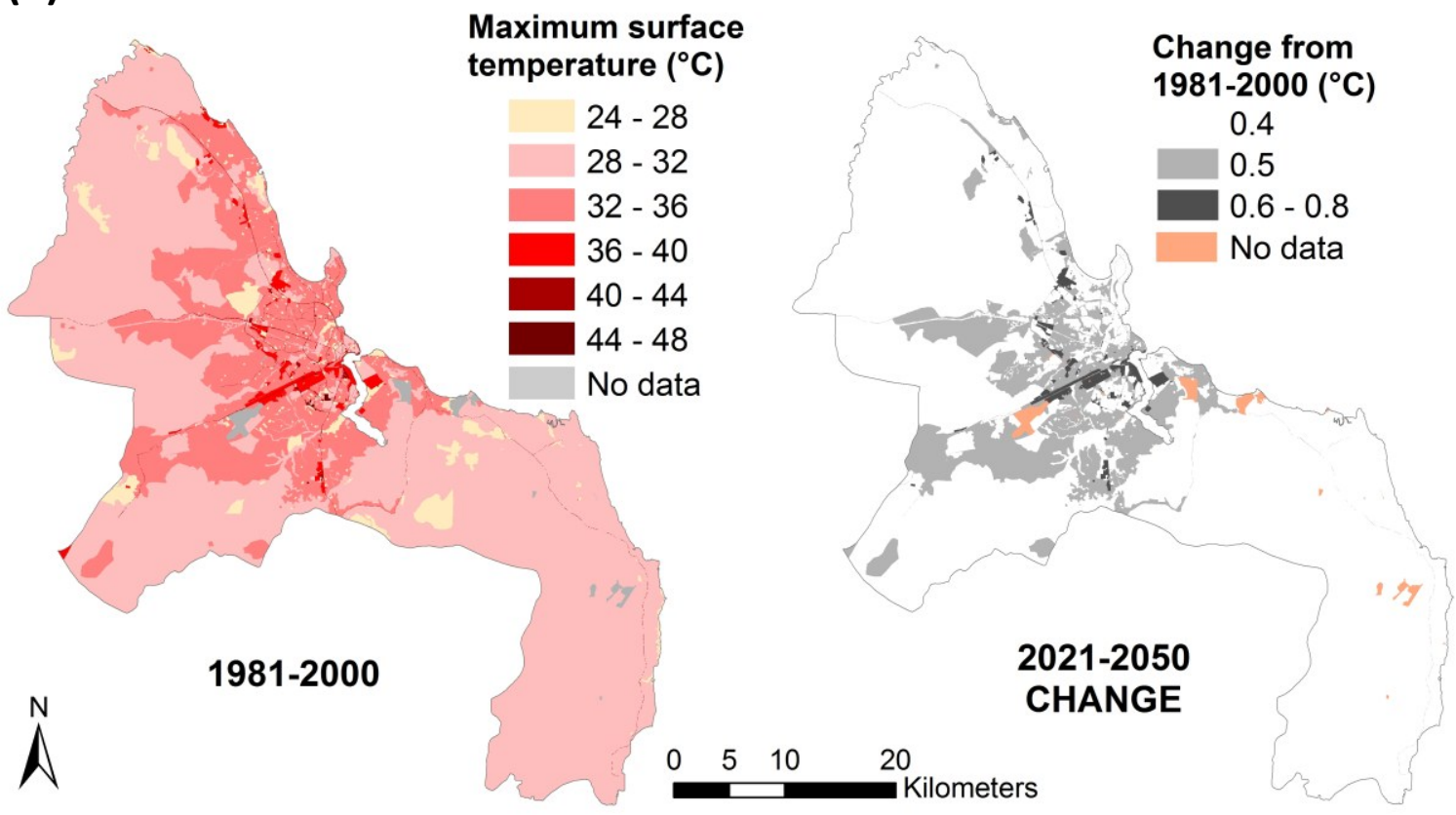

309 Figure 4: Modelled maximum surface temperatures 1981-2000 and changes to 2021-2050 
311 Figure 5 illustrates the strong relationship between the surface temperature and evaporating 312 fraction (vegetated and water surfaces). This relationship is not perfectly linear due to variations in 313 other variables including type and proportion of buildings and impervious surfaces (built mass), but there is a very high inverse correlation between the two ( -0.85 Pearson's Product Moment correlation coefficient). There is a very large range in the evaporating fraction (green structure and water), which is at a minimum at around just $4 \%$ in Open Markets UMTs for both cities, and greatest for Bushland UMT (85\%) and River UMT (99\%) in Dar es Salaam and Vegetable farms UMT (8\%) in Addis Ababa. Ignoring the UMTs that are mostly green (Agriculture and Vegetation Primary UMTs), the Education UMT in Dar es Salaam and Palace UMT in Addis Ababa have the lowest surface temperatures and therefore good supply of temperature regulation ecosystem services. However, the Palace UMT covers less than $1 \%$ of the area of Addis Ababa, so is not a key service provider. It is evident that whilst air temperatures are higher in Dar es Salaam compared to Addis Ababa, surface temperatures are lower. This is explained by the higher overall evaporating fraction and lower proportions of bare soil across the majority of UMTs in Dar es Salaam. There are some differences in the maximum surface temperatures of residential UMT categories in the cities. Whilst Condominium UMT has the highest surface temperatures of all Residential UMTs in Addis Ababa, it is amongst the lowest in Dar es Salaam. In Addis Ababa, the Mud/wood construction UMT has a higher evaporating fraction and therefore lower surface temperatures than other Residential UMT classes. The building mass also affects this result, since these housing types have a much lower building mass than that associated with Villa and single storey UMTs, due to the size of the buildings and the type of 
(a) Addis Ababa

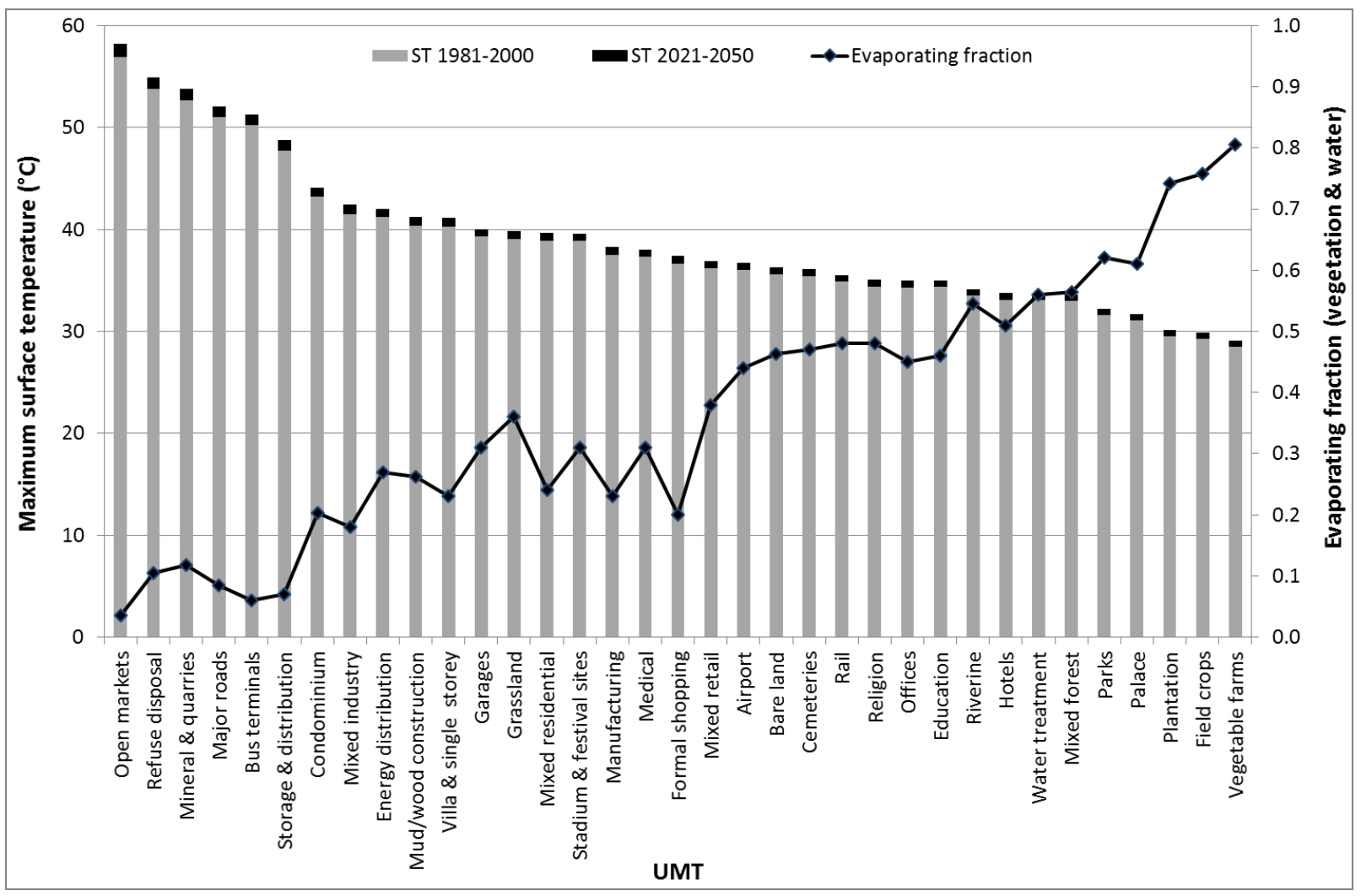

(b) Dar es Salaam

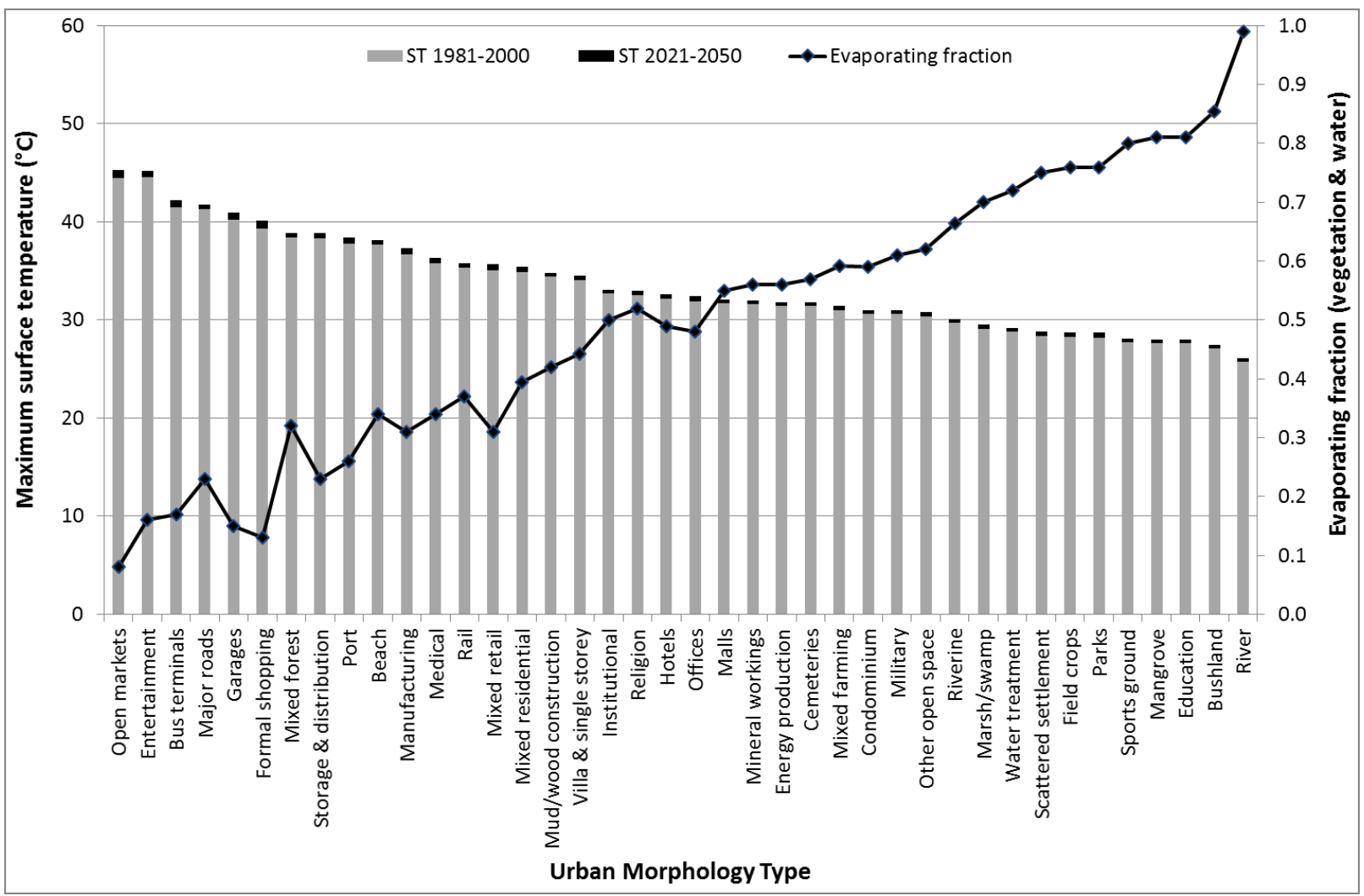

Figure 5: Modelled maximum surface temperatures and evaporating fraction (green space and water) by UMT (a) Addis Ababa (b) Dar es Salaam 


\section{Discussion}

The primary UMT class with the largest area within both cities is residential, totalling around $47 \%$ and $35 \%$ of the land area in Dar es Salaam and Addis Ababa respectively (Table 1). As population growth is increasing pressure on housing demands and driving rapid growth of residential areas, it is important to look at the detailed residential UMTs in particular to understand the provision for temperature regulation ecosystem services. In addition, current planning policies in African cities aim to convert high density informal unplanned settlements areas to formal planned housing types, and such changes will have consequences for provision of temperature regulation services.

The results show that in Dar es Salaam, Scattered settlements and Condominium UMTs are much better placed to provide temperature regulation services than other residential UMTs due to their urban morphology characteristics, specifically since both are associated with relatively large proportions of green structures. However, scattered settlements are by definition not formally part of the main urban area and therefore their green structures are not strictly contributing to urban ecosystem services. This contrasts to Addis Ababa where Condominium UMTs have the lowest amount of green structure compared to other residential types, and Mixed residential and Mud/wood construction UMTs are best at mitigating high temperatures. This is an important issue since current planning policies aim to convert high density informal housing areas of the Mud/wood construction UMT to formal housing types including Condominium and Villa \& single storey UMTs. Such changes would reduce the effectiveness of residential UMTs in providing temperature regulation services.

The quality of green structure is also important in determining the effectiveness of temperature regulation services provision. This includes the combination of land surface cover types, whereby trees over grass is the most effective landscape strategy, due to provision of both cooling through evapotranspiration and shade (Shashua-Bar et al., 2009). Whilst the energy exchange model is not detailed enough to consider the composition of green structure types and their effect on surface temperatures, the land cover assessment provides additional detail about the relative proportions of different green structures within the UMTs. Comparison of the green space in residential UMTs in the two cities reveals firstly how much less green structure Addis Ababa has in residential areas compared to Dar es Salaam (Figure 6). Thus, whilst Addis Ababa experiences lower air temperatures than Dar es Salaam, urban morphological characteristics mean that surface temperatures are actually higher in Addis Ababa than in Dar es Salaam. This highlights the importance of bringing additional green structures more generally to residential areas in Addis Ababa. Indeed, this issue is already being considered as part of the latest Addis Ababa Masterplan, which favours establishing smaller areas of green space within residential units due to the problem of finding suitable areas to establish large green spaces and parks. These results also highlight the need to retain existing green structures in Dar es Salaam to avoid land cover driven increases in surface temperatures. In Dar es Salaam, a bigger issue is the establishment of additional green structures in Mud/wood construction UMTs, not least as these are the areas that the most socially vulnerable populations are likely to live. 


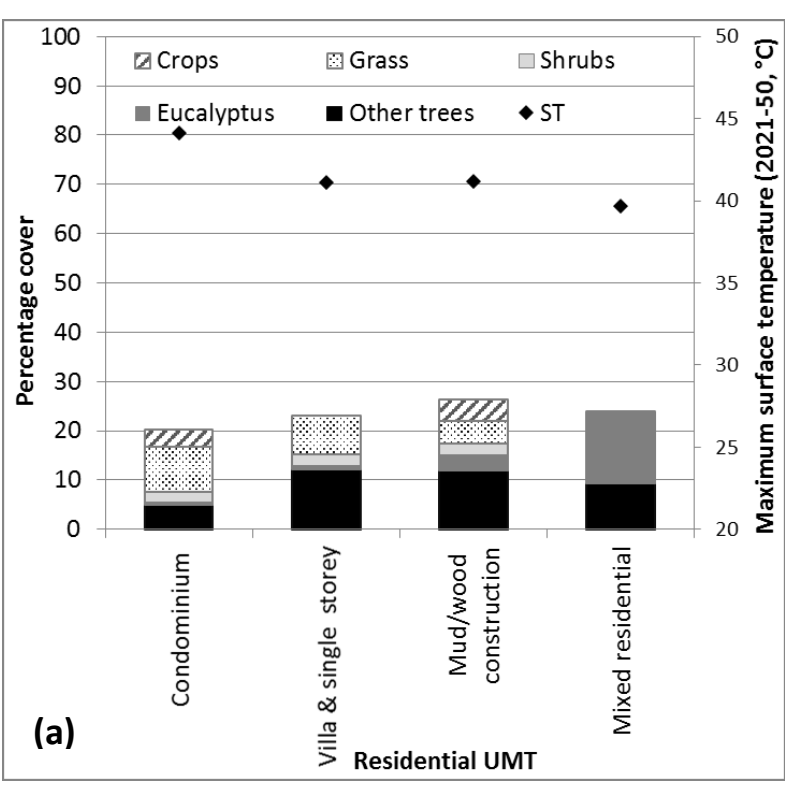

Figure 6: Quality of green space in Residential UMTs

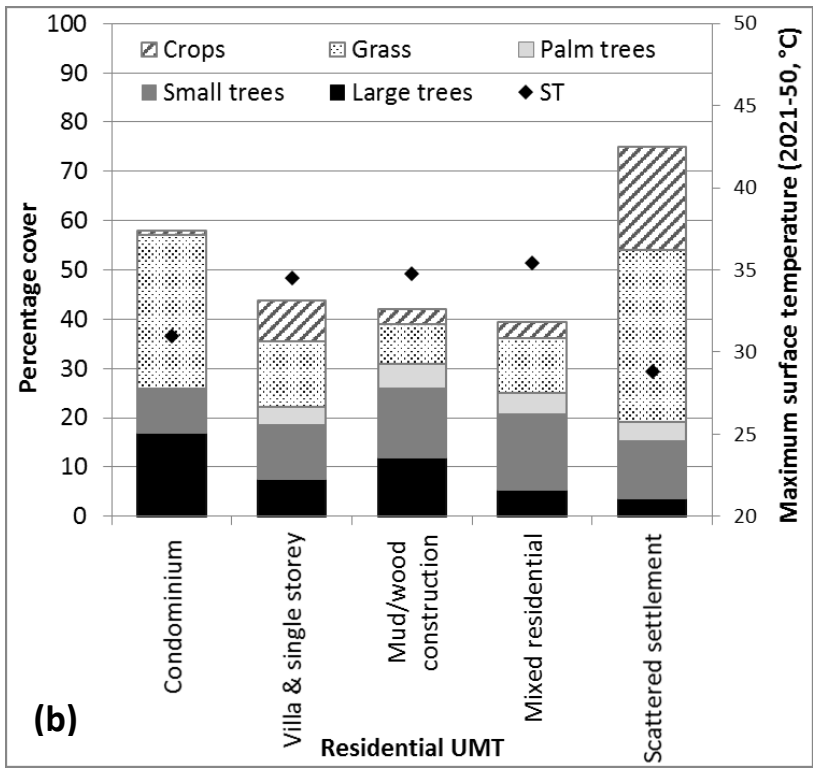

(a) Addis Ababa (b) Dar es Salaam

In the case of Addis Ababa, the land surface cover analysis shows that Mud/wood construction UMTs have both larger amounts of green space and arguably higher quality green space, with a greater proportion of large trees compared to both Condominium and Villa \& single storey UMTs (Figure 6). Therefore, Mud/wood construction UMTs provide better temperature regulation services than other residential UMTs. A lower building mass in Mud/wood construction UMTs also acts to lower the surface temperatures. This is a particularly important issue because the urban renewal strategy of Addis Ababa municipality aims to densify the city by converting all mud/wood housing types in informal settlements into condominiums. Thus, increasing Condominium UMT areas will increase impervious surfaces, built mass, and reduce the quantity and quality of green structure, reducing the capacity for provision of temperature regulation services.

In Dar es Salaam, excluding scattered settlements (due to their distance from the urban centre and therefore incomparability to other residential areas), Condominium UMTs have not only the largest amount of green space, but also the highest quality green space, with the greatest proportion of large trees providing more shade from high temperatures due to their larger crown size.

Additionally, despite their informal and unplanned nature, Mud/wood construction UMTs have good quality green structures, with a similar proportion of trees to Condominium UMTs, though fewer proportions of large trees ( $12 \%$ compared to $17 \%$ in Condominium UMTs). As this residential type is upgraded into formal residential areas, it is essential that the quality of green structure remains.

Findings from both cities therefore indicate that unlike many European cities, there is little evidence suggesting that higher class residential areas, including Villa and single storey UMTs, have more green space and therefore better provision of temperature regulation services, particularly demanded during heat waves. However, the characteristics of housing also matter to a large extent, with different housing types providing different insulation properties and protecting from heat and cold to different extents, directly impacting on temperature-related mortality (Scovronick and Armstrong, 2012). Interestingly, analysis suggests that traditionally constructed housing provides more protection from heat than formal low-cost housing (Scovronick and Armstrong, 2012). This should be borne in mind in African cities where the focus is on upgrading unplanned residential areas which includes traditionally constructed housing. 
Exposure of the urban population is not just associated with where people live but also where they work and how they travel. Whilst the modelling only accounts for evaporative cooling, shading is also a very important ecosystem service. Trees with large crowns are particularly needed for shading pedestrian streets in Addis Ababa as they are largely absent, exacerbating high temperatures and forcing people to use public transport to travel even short distances. However, in order to establish such street trees there is a need to understand which indigenous tree species would best suit the harsher conditions associated with such locations.

Whilst research shows that there is often strong spatial correlations between the provision of different ecosystem services, e.g. resulting in service hotspots (Wu et al., 2013), it does not necessarily follow that these hotspots match the needs and demands of society (Burkhard et al., 2012). This is particularly the case for Addis Ababa, where green space is mostly retained in traditionally green areas including Agriculture and Vegetation UMTs, and where temperature regulation services are most required - in residential areas - green space is distinctly lacking.

\section{Uncertainty, limitations and further considerations}

It was stressed that the assessment for both cities is valid only for the dry season (DecemberFebruary). This was chosen primarily due to the availability of aerial photographs, but also matches the occurrence of high temperatures and heat waves in the cities, and therefore, it is when temperature regulation services are most needed. Green structure phonological responses in East Africa are known to be strongly precipitation driven (Zhang et al., 2005), and an assessment of temperature regulation ecosystem services in the rainy season would be likely to yield very different results. In addition, the accuracy of land surface cover information derived from the dry season orthophotos may have some limitations, in particular because grasses and field crops are very easy to miss-classify as bare land (Cavan et al., 2012), thus underestimating the temperature regulation services that may be available.

As with all modelling approaches, the reliability of the model output is strongly reliant on the quality of input parameters. Whilst it is challenging to source some model input parameters at a local level, the best information available was used to construct the model and all input parameters and calculation methods are transparent. Further, model sensitivity testing illustrates that changing any model parameter by $10 \%$ results in a change in surface temperatures by a maximum of $1.5^{\circ} \mathrm{C}$ (Gill, 2006). Since such changes would apply across all UMTs, the relative differences between UMTs would remain similar. Parameters that most affect the surface temperature output include peak insolation, wind velocity at the surface boundary layer, evaporative fraction and parameters relating to the reference temperature (Gill, 2006).

The results are likely to be applicable to many other African cities, particularly in similar climate zones (CWB and Aw for Addis Ababa and Dar es Salaam respectively). Results may be less transferable to African cities experiencing prolonged and significant droughts, placing stress on plants and affecting their evapotranspiration processes. Additional consideration should be given to plants adapted to arid conditions that carry out CAM photosynthesis, thereby closing their stomata during the day to reduce evapotranspiration and opening them at night to capture carbon dioxide (Allen et al., 1998). Such species are less common in Addis Ababa and Dar es Salaam cities, namely due to their adequate rainfall, and therefore were not investigated further. One possibility to address this issue for arid areas is by applying a reduction factor to the evapotranspiring fraction.

\section{Conclusion}

This study outlined the first comprehensive assessment of urban morphological characteristics and the impact on temperature regulation services for two African cities: Addis Ababa, Ethiopia and Dar 
es Salaam, Tanzania. Green structures provide important temperature regulation services through cooling the local environment via evapotranspiration, shading, and re-radiating less heat than builtup surfaces. Urban Morphology Types (UMTs) provide a good framework for assessing ecosystem services and land use planning.

UMT classification resulted in the identification of 35 and 43 detailed UMT classes in Addis Ababa and Dar es Salaam respectively. Over $40 \%$ of the land area of both cities is associated with sub-UMT classes which are primarily green in nature. Proportional land surface cover results mapped onto the UMT categories revealed the spatial distribution of built and evapotranspiring (vegetation and water) surfaces across the cities, highlighting the existence of green structures outside those subUMTs traditionally considered green. The urban morphological characteristics of the two cities resulted in different spatial patterns of the provision of temperature regulation services across the cities. In fact, land surface cover differences drive land surface temperature ranges over $25^{\circ} \mathrm{C}$ compared to climate change projections being associated with changes of less than $1.5^{\circ} \mathrm{C}$. Whilst air temperatures are higher in Dar es Salaam, modelled surface temperatures are higher in Addis Ababa, due to the lower proportions of green structure, and greater amounts of impervious surfaces and bare soil across the city. This highlights the importance of bringing additional green structures more generally to UMTs in Addis Ababa, other than retaining it in traditionally 'green' Agriculture and Vegetation UMTs.

Finally, focussed investigation of quantity and quality of green structure in residential UMTs revealed that in Addis Ababa, informal settlements and traditional housing areas have higher proportions and better composition of green structures than other residential areas, and are thus associated with the lowest modelled land surface temperatures. In Dar es Salaam, condominium UMTs have some of the largest proportions of green structures, and the best provision of temperature regulation services. These results have implications for current planning policies in African cities which aim to convert high density informal unplanned settlements areas to formal planned housing types. Such urban morphological changes will have consequences for land surface cover and therefore affect the future provision of temperature regulation services.

\section{References}

Adebayo, Y.R. (1990). Considerations for Climate-sensitive Design in Tropical Africa. Energ Buildings 15-16: 15-21.

Allen, R.G. Pereira, L.S. Raes, D. and Smith, M. (1998). Crop evapotranspiration: guidelines for computing crop water requirements. FAO Irrigation and Drainage Paper 56. FAO, Rome, Italy.

Bastian, O. Haase, D. and Grunewald, K. (2012). Ecosystem properties, potentials and services - The EPPS conceptual framework and an urban application example. Ecol Indic 21: 7-16.

Bolund, P. and Hunhammar, S. (1999). Ecosystem services in urban areas. Ecol Econ 29(2): 293-301.

Bowler, D.E. Buyung-Ali, L. Knight, T.M. and Pullin, A.S. (2010). Urban greening to cool towns and cities: A systematic review of the evidence. Landsc Urban Plan 97: 147-155.

Boyd, J. and Banzhaf, S. (2007). What are ecosystem services? Ecol Econ 63: 616-626.

Brown, R.D. and Gillespie, T.J. (1995). Microclimate Landscape Design: Creating Thermal Comfort and Energy Efficiency. John Wiley \& Sons, Chichester.

Burkhard, B. Kroll, F. Nedkov, S. and Muller, F. (2012). Mapping ecosystem service supply, demand and budgets. Ecol Indic 21: 17-29. 
512

513

514

515

516

517

518

519

520

521

522

523

524

525

526

527

528

529

530

531

532

533

534

535

536

537

538

539

540

541

542

543

544

545

546

547

548

549

550

551

552

553

554

555

556

557

558

559

560

561

562

Busch, M. La Notte, A. Laporte, V. and Erhard, M. (2012). Potentials of quantitative and qualitative approaches to assessing ecosystem services. Ecol Indic 21: 89-103.

Cavan, G. Lindley, S. Roy, M. Woldegerima, T. Tenkir, E. Yeshitela, K. Kibassa, D. Shemdoe, R. Pauleit, S., Renner, R. Printz, A. and Ouédraogo, Y. (2011). A database of international evidence of the ecosystem services of urban green structure in different climate zones. CLUVA Deliverable 2.6. Available at http://www.cluva.eu/deliverables/CLUVA D2.6.pdf (accessed 18 July 2013).

Cavan, G. Lindley, S. Yeshitela, K. Nebebe, A. Woldegerima, T. Shemdoe, R. Kibassa, D. Pauleit, S. Renner, R. Printz, A. Buchta, K. Coly, A. Sall, F. Ndour, N.M. Ouédraogo, Y. Samari, B.S. Sankara, B.T. Feumba, R.A. Ngapgue, J.N. Ngoumo, M.T. Tsalefac, M. and Tonye, E. (2012). Green infrastructure maps for selected case studies and a report with an urban green infrastructure mapping methodology adapted to African cities. CLUVA Deliverable D2.7. Available at http://www.cluva.eu/deliverables/CLUVA D2.7.pdf (accessed 18 July 2013).

Christensen, J.H. B. Hewitson, A. Busuioc, A. Chen, X. Gao, I. Held, R. Jones, R.K. Koli, W.T. Kwon, R. Laprise, V.M. Rueda, L. Mearns, C.G. Menéndez, J. Räisänen, A. Rinke, A. Sarr and P. Whetton,. (2007). Regional climate projections. Climate Change 2007: The Physical Science Basis. Contribution of Working Group I to the Fourth Assessment Report of the Intergovernmental Panel on Climate Change, S. [Solomon, D. Qin, M. Manning, Z. Chen, M. Marquis, K.B. Averyt, M. Tignor and H.L. Miller, (Eds.)], Cambridge University Press, Cambridge, 847-940.

Cilliers, S. Cilliers, J. Lubbe, R. and Siebert, S. (2012). Ecosystem services of urban green spaces in African countries - perspectives and challenges. Urban Ecosystems. DOI 10.1007/s11252-012-0254-3.

CSIR and CMCC (2012).CLUVA deliverable D1.5 Regional climate change simulations available for the selected areas.Available at http://www.cluva.eu/deliverables/CLUVA D1.5.pdf. Accessed 18 July 2013.

Dousset, B. Gourmelon, F. Laaidi, K. Zeghnoun, A. Giraudet, E. Bretin, P. Mauri, E. and Vandentorren, S. (2011). Satellite monitoring of summer heat waves in the Paris metropolitan area. Int J Climatol 31(2): 313-323.

Emmanuel, R. and Johansson, E. (2006). Influence of Urban Morphology and Sea Breeze on Hot Humid Microclimate: The Case of Colombo, Sri Lanka. Climate Res 30: 189-200.

Giugni, M. Adamo, P. Capuano, P. De Paola, F. Di Ruocco, A. Giordano, S. lavazzo, P. Sellerino, M. Terracciano, S. and Topa, M. E. (2012). CLUVA deliverable D.1.2 Hazard scenarios for test cities using available data. Available at http://www.cluva.eu/deliverables/CLUVA D1.2.pdf (accessed 8 Jan 2012).

Gill, S. (2006). Climate change and urban greenspace. PhD thesis, University of Manchester, UK.

Gill, S.E. Handley, J.F. Ennos, A.R. and Pauleit, S. (2007). Adapting cities for climate change: the role of the green infrastructure. Built Environ 33: 115-133.

Gill, S. Handley, J. Ennos, R. Pauleit, S. Theuray, N. and Lindley, S. (2008) Characterising the urban environment of UK cities and towns: A template for landscape planning. Landsc Urban Plan 87(3): 210-222. 
Gualdi, S. Somot, S. Li, L. Artale, V. Adani, M. Bellucci, A. Braun, A. Calmanti, S. Carillo, A. Dell'Aquila, A. Dqu, M. Dubois, C. Elizalde, A. Harzallah, A. Jacob, D. L'Hvder, B. May, W. Oddo, P. Ruti, P. Sanna, A. Sannino, G. Scoccimarro, E. Sevault, F. and Navarra, A. (2013). The CIRCE Simulations: Regional Climate Change Projections with Realistic Representation of the Mediterranean Sea. B Am Meteorol Soc 94: 65-81.

Kottek, M. Grieser, J. Beck, C. Rudolf, B. and Rubel, F. (2006). World Map of the Köppen-Geiger climate classification updated. Meteorologische Zeitschrift 15(3): 259-263.

Kumar, P. and Wood, M.D. (2010). An Introduction to the valuation of regulating services. In P. Kumar and M.D. Wood, (eds), Valuation of Regulating Services of Ecosystems: Methodology and Applications, Routledge: Oxon and New York, 1-10.

Laaidi, K. Zeghnoun, A. Dousset, B. Bretin, P. Vandentorren, S. Giraudet, E. and Beaudeau, P. (2012). The impact of heat islands on mortality in Paris during the August 2003 heat wave. Environ Health Persp 120(2): 254-259.

Layke, C. Mapendembe, A. Brown, C. Walpole, M. and Winn, J. (2012). Indicators from the global and sub-global Millennium Ecosystem Assessments: An analysis and next steps. Ecol Indic 17: 77-87.

Lindley, S. J. Handley, J.F. McEvoy, D. Peet, E. and Theuray, N. (2007).The role of spatial risk assessment in the context of planning for adaptation in UK urban areas. Built Environ 33(1): 46-69.

Lupala, J.M. (2002). Urban types in rapidly urbanising cities. Analysis of formal and informal settlements in Dar es Salaam, Tanzania. Doctoral thesis, Department of Infrastructure and Planning, KTH Royal Institute of Technology, Stockholm.

Matzarakis, A. Mayer, H. and Iziomon, M. (1999). Applications of a universal thermal index: physiological equivalent temperature. International Journal of Biometeorology 43: 76-84. MEA (2005). Ecosystems and Human Well-being: A Framework for Assessment, Island Press, Washington DC.

Mines ParisTech / Armines (2006). HelioClim-3 service. http://project.mesor.net/web/guest/hc3 (accessed 20 June 2013). Moudon, A.V. (1997). Urban Morphology as an emerging interdisciplinary field. Urban Morphology 1: 3-10.

Nyarirangwe, M. (2008). The impact of multi-nucleated city morphology on transport in Addis Ababa. In van Dijk, M.P. and Fransen, J. (Eds). Managing Ethiopian cities in an era of rapid urbanization. Eburon Uitgeverij BV.

Pauleit, S. and Duhme, F. (2000). Assessing the Environmental Performance of Land Cover Types for Urban Planning. Landsc Urban Plan 52 (1): 1-20.

Pauleit, S. Breuste, J. and Qureshi, S. (2010). Transformation of rural-urban cultural landscapes in Europe: Integrating approaches from ecological, socio-economic and planning perspectives. Landsc Online 20: 1-10.

Romero-Lankao, P. Qin, H. and Dickinson, K. (2012). Urban vulnerability to temperature-related hazards: A meta-analysis and meta-knowledge approach. Glob Environ Change 22: 670-683. 
Roth, M. (1997). Review of urban climate research in (sub)tropical regions. Int J Climatol 27: 18591873.

Scovronick, N. and Armstrong, B. (2012). The impact of housing type on temperature-related mortality in South Africa, 1996-2015. Environ Res 113: 46-51.

Schwarz, N. Scholink, U. Franck, U. and Großmann, K. (2012). Relationship of land surface and air temperatures and its implications for quantifying urban heat island indicators - An application for the city of Leipzig (Germany). Ecol Indic 18: 693-704.

Stephenson, D.B. (2008). Definition, diagnosis, and origin of extreme weather and climate events. In Diaz, H. and Murnane, R. (Eds), Climate extremes and society, chapter 1, pages 11-23. Cambridge University Press.

Tanroads (1999). Pavement and Materials Design Manual - 1999. The United Republic of Tanzania Ministry of Works.

The Mersey Forest and The University of Manchester (2011). STAR tools: surface temperature and runoff tools for assessing the potential of green infrastructure in adapting urban areas to climate change. Part of the EU Interreg IVC GRaBS project. www.ppgis.manchester.ac.uk/grabs.

Tso, C.P. Chan, B.K. and Hashim, M.A. (1990). An improvement to the basic energy balance model for urban thermal environment analysis. Energ Buildings 14(2): 143-152.

Tso, C.P. Chan, B.K. and Hashim, M.A. (1991). Analytical solutions to the near-neutral atmospheric surface energy balance with and without heat storage for urban climatological studies. J Appl Meteorol 30(4): 413-424.

United Nations (2012). World Urbanization Prospects: The 2011 Revision. Highlights. United Nations Department of Economic and Social Affairs/Population Division, UN, New York. Available at: http://esa.un.org/unup/pdf/WUP2011 Highlights.pdf (accessed 24 July 2013).

von Engeln, A. and Teixeira, J. (2013). A Planetary Boundary Layer Height Climatology derived from ECMWF Re-analysis Data. J Clim. DOI: 10.1175/JCLI-D-12-00385.1

Whitford, V. Ennos, A.R. and Handley, J.F. (2001). "City form and natural process" - indicators for the ecological performance of urban areas and their application to Merseyside, UK. Landsc Urban Plan 57(2): 91-103.

Wu, J. Feng, Z. Gao, Y. and Peng, J. (2013). Hotspot and relationship identification in multiple landscape services: A case study on an area with intensive human activities. Ecol Indic 29: 529-537.

Zhang, X. Friedl, M.A. Schaaf, C.B. Strahler, A.H. and Liu, Z. (2005). Monitoring the response of vegetation phenology to precipitation in Africa by coupling MODIS and TRMM instruments. Journal of Geophysical Research: Atmospheres (1984-2012), 110(D12).

Zhou, W. Huang, G. and Cadenasso, M.L. (2011). Does spatial configuration matter? Understanding the effects of land cover pattern on land surface temperatures in urban landscapes. Landsc Urban Plan 102: 54-63. 


\section{Acknowledgements}

This research was funded by the European Commission's seventh framework program Climate Change and Urban Vulnerability in Africa (CLUVA), FP7-ENV-2010, Grant No. 265137. This support is gratefully acknowledged. We also acknowledge Dr Ingo Simonis for providing climate projections data, and Mr. Nebyou Yonas and Ms. Elinorata Mbuya for providing building details for Addis Ababa and Dar es Salaam city respectively.

\section{Appendix A: Energy exchange model input parameters}

\begin{tabular}{|c|c|c|c|c|}
\hline Parameter & Addis Ababa & $\begin{array}{l}\text { Dar es } \\
\text { Salaam }\end{array}$ & Unit & Reference \\
\hline Reference temperatures & $\begin{array}{l}\text { 1981-00: } \\
\text { 27.42/24.06 } \\
\text { 2021-50: } \\
28.39 / 25.24\end{array}$ & $\begin{array}{l}\text { 1981-00: } \\
31.29 \\
2021-50: \\
32.41\end{array}$ & ${ }^{\circ} \mathrm{C}$ & $\begin{array}{l}\text { Coupled General Circulation Model } \\
\text { (CGCM) simulations, A2 IPCC emissions } \\
\text { scenario (CSIR and CMCC, 2012) }\end{array}$ \\
\hline Sunrise time & 0600 & 0600 & hours & \multirow{2}{*}{$\begin{array}{l}\text { Average for Dec-Feb; Astronomical } \\
\text { Applications Department U.S. Naval } \\
\text { Observatory }\end{array}$} \\
\hline Sunset time & 1800 & 1800 & hours & \\
\hline Specific heat of air & 1006 & 1006 & $\mathrm{~J} / \mathrm{kg} /{ }^{\circ} \mathrm{C}$ & Assumption \\
\hline Soil depth & 20 & 20 & $\mathrm{~cm}$ & Assumption \\
\hline Thermal conductivity of soil & 1.083 & 1.083 & $\mathrm{~W} / \mathrm{m} /{ }^{\circ} \mathrm{C}$ & \multirow{3}{*}{$\begin{array}{l}\text { Average for sandy and clay, dry and } \\
\text { saturated soil (Oke, 1987: 4) }\end{array}$} \\
\hline Specific heat of soil & 1180 & 1180 & $\mathrm{~J} / \mathrm{kg} /{ }^{\circ} \mathrm{C}$ & \\
\hline Density of soil & 1800 & 1800 & $\mathrm{~kg} / \mathrm{m}^{3}$ & \\
\hline Specific heat of concrete & 880 & 880 & $\mathrm{~J} / \mathrm{kg} /{ }^{\circ} \mathrm{C}$ & Holman (1986) \\
\hline $\begin{array}{l}\text { Building mass/unit built } \\
\text { land }\end{array}$ & $\begin{array}{l}\text { Type I = } \\
2010.62 \\
\text { Type } 2= \\
960.71\end{array}$ & $\begin{array}{l}\text { Type I = } \\
2054.92 \\
\text { Type } 2= \\
907.75\end{array}$ & $\mathrm{~kg} / \mathrm{m}^{2}$ & $\begin{array}{l}\text { Calculated from typical buildings in case } \\
\text { study cities }\end{array}$ \\
\hline $\begin{array}{l}\text { Weighted UMT building } \\
\text { mass }\end{array}$ & $\begin{array}{l}\text { Varies with } \\
\text { UMT }\end{array}$ & $\begin{array}{l}\text { Varies with } \\
\text { UMT }\end{array}$ & $\mathrm{kg} / \mathrm{m}^{2}$ & \\
\hline Major road mass & 411 & 362 & $\mathrm{~kg} / \mathrm{m}^{2}$ & \multirow{2}{*}{$\begin{array}{l}\text { Calculated from Tanroads (1999); Gill } \\
\text { (2006) and Yeshitela (pers. comm.) }\end{array}$} \\
\hline $\begin{array}{l}\text { Other impervious surfaces } \\
\text { mass }\end{array}$ & 383 & 292 & $\mathrm{~kg} / \mathrm{m}^{2}$ & \\
\hline Roughness length & 2 & 2 & $\mathrm{~m}$ & Average height of buildings (assumption) \\
\hline $\begin{array}{l}\text { Height of surface boundary } \\
\text { layer }\end{array}$ & 1957 & 1468 & $\mathrm{~m}$ & $\begin{array}{l}\text { Average Dec-Feb (von Engeln and } \\
\text { Teixeira, 2013) }\end{array}$ \\
\hline $\begin{array}{l}\text { Wind velocity at surface } \\
\text { boundary layer }\end{array}$ & 5 & 5 & $\mathrm{~m} / \mathrm{s}$ & Assumption \\
\hline $\begin{array}{l}\text { Specific humidity at surface } \\
\text { boundary layer }\end{array}$ & 0.002 & 0.002 & & Assumption \\
\hline Peak insolation & 1247 & 1050 & $\mathrm{~W} / \mathrm{m}^{2}$ & $\begin{array}{l}\text { Mines ParisTech / Armines (2006), 90 } \\
\text { percentile Dec-Feb }\end{array}$ \\
\hline Night radiation & -93 & -148.7 & $\mathrm{~W} / \mathrm{m}^{2}$ & Assumption \\
\hline
\end{tabular}




\section{Appendix B: Example calculation of building mass - building type II in Dar es Salaam}

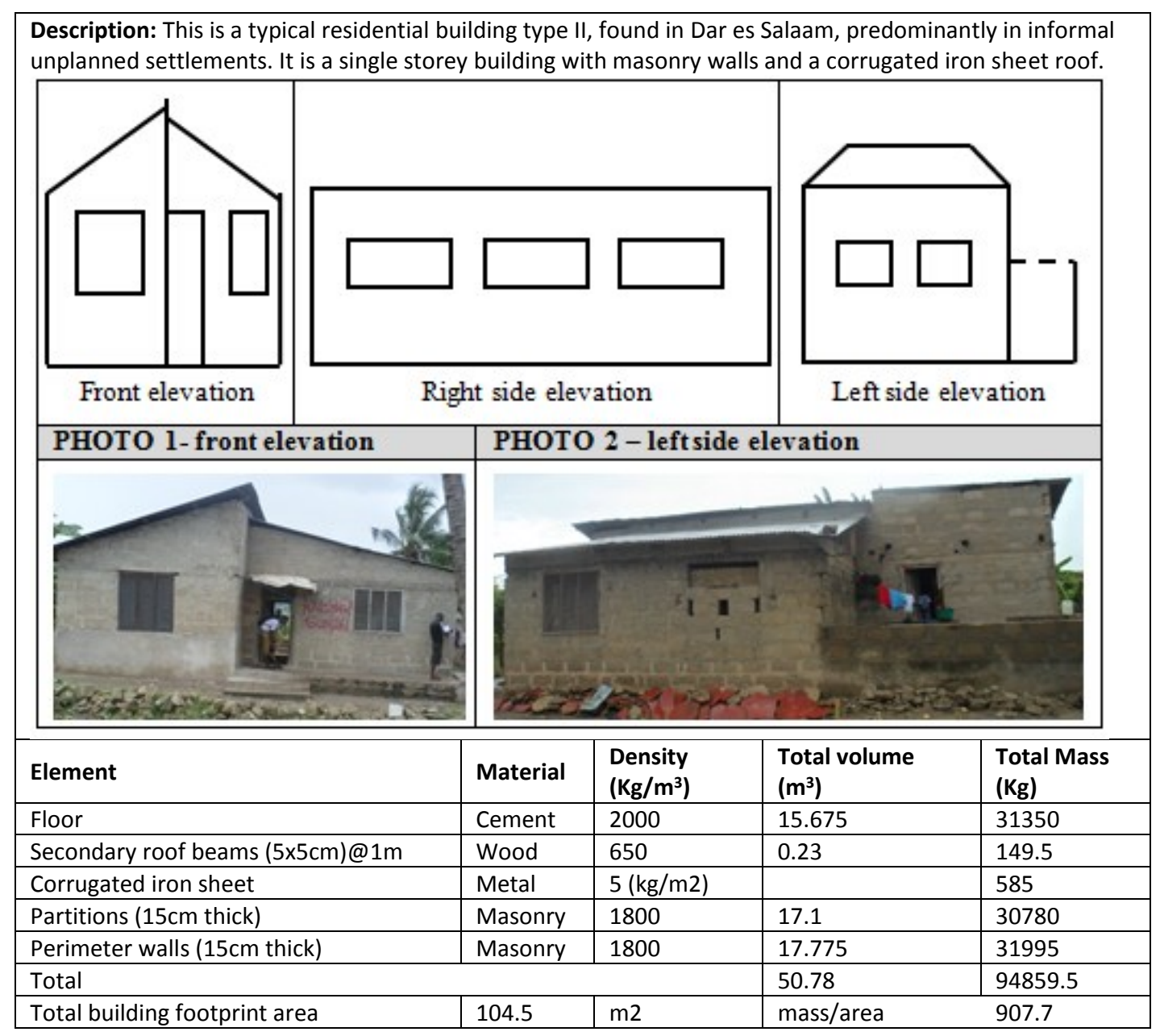


Appendix C: Mass of road layers in the case study cities (from Tanroads (1999); Gill (2006) and Yeshitela, pers. comm.)

\begin{tabular}{|c|c|c|c|c|}
\hline \multirow{2}{*}{ ROAD LAYER } & \multicolumn{2}{|c|}{ Major roads } & \multicolumn{2}{|c|}{ Other impervious } \\
\hline & Dar es Salaam & Addis Ababa & Dar es Salaam & Addis Ababa \\
\hline $\begin{array}{l}\text { SURFACE: } \\
\text { Wearing \& binder } \\
\text { course / surfacing }\end{array}$ & $\begin{array}{l}\text { Asphalt concrete } 5 \mathrm{~cm}- \\
116 \mathrm{~kg} / \mathrm{m}^{2}\end{array}$ & $\begin{array}{l}\text { Asphalt concrete } 5 \mathrm{~cm}- \\
116 \mathrm{~kg} / \mathrm{m}^{2}\end{array}$ & $\begin{array}{c}\text { Bituminous seal } 1 \mathrm{~cm}-46 \\
\mathrm{~kg} / \mathrm{m}^{2}\end{array}$ & $\begin{array}{l}\text { Asphalt concrete } 2.5 \mathrm{~cm}- \\
58 \mathrm{~kg} / \mathrm{m}^{2} \\
\text { Gravel } 1.8 \mathrm{~cm}-30 \mathrm{~kg} / \mathrm{m}^{2}\end{array}$ \\
\hline $\begin{array}{l}\text { BASE: } \\
\text { Gravel wearing } \\
\text { course }\end{array}$ & Gravel $15 \mathrm{~cm}-246 \mathrm{~kg} / \mathrm{m}^{2}$ & $\begin{array}{c}\text { Granular material } 18 \mathrm{~cm}- \\
295 \mathrm{~kg} / \mathrm{m}^{2}\end{array}$ & Gravel $15 \mathrm{~cm}-246 \mathrm{~kg} / \mathrm{m}^{2}$ & $\begin{array}{c}\text { Granular material } 18 \mathrm{~cm}- \\
295 \mathrm{~kg} / \mathrm{m}^{2}\end{array}$ \\
\hline $\begin{array}{l}\text { SUB-BASE: } \\
\text { Structural layer / } \\
\text { improved sub- } \\
\text { grade }\end{array}$ & Gravel $30 \mathrm{~cm}$ & Granular material $25 \mathrm{~cm}$ & Gravel $30 \mathrm{~cm}$ & Granular material $25 \mathrm{~cm}$ \\
\hline SUB-GRADE: & Soil & Soil & Soil & Soil \\
\hline Total mass & $362 \mathrm{~kg} / \mathrm{m}^{2}$ & $411 \mathrm{~kg} / \mathrm{m}^{2}$ & $292 \mathrm{~kg} / \mathrm{m}^{2}$ & $383 \mathrm{~kg} / \mathrm{m}^{2}$ \\
\hline
\end{tabular}

